\title{
Risk factors for failure of single-level percutaneous endoscopic lumbar discectomy
}

\author{
${ }^{*}$ Hongwei Wang, MD, PhD, ${ }^{1}$ Yue Zhou, MD, PhD, ${ }^{2}$ Changqing Li, MD, PhD, ${ }^{2}$ Jun Liu, MD, PhD, ${ }^{1}$ and \\ Liangbi Xiang, MD, PhD'
}

\begin{abstract}
'Department of Orthopedics, General Hospital of Shenyang Military Area Command of Chinese PLA, Shenyang, Liaoning; and 2Department of Orthopedics, Xinqiao Hospital, The Third Military Medical University, Chongqing, China
\end{abstract}

\begin{abstract}
OBJECT Few studies have addressed surgical failures and complications following percutaneous endoscopic lumbar discectomy (PELD), and no previous study has investigated the risk factors that lead to surgical failure. The authors report their experience using PELD for single-level lumbar disc herniation (LDH) to provide insights into the rates of surgical failure and identify potential risk factors that lead to this complication.
\end{abstract}

METHODS The authors retrospectively reviewed the medical records of 350 patients who underwent PELD for singlelevel LDH and identified 36 patients (10.3\%) who underwent reoperation due to the failure of PELD.

RESULTS Patients' mean visual analog scale of pain scores and Oswestry Disability Index scores improved significantly from $6.6 \pm 2.1$ and $51.6 \pm 19.4$ preoperatively to $1.9 \pm 1.4$ and $28.3 \pm 12.0$, respectively, at 1 month postoperatively and $1.2 \pm 1.1$ and $9.3 \pm 7.8$, respectively, at 1 year postoperatively. The frequencies with which patients took analgesic medications significantly decreased from $74.6 \%$ preoperatively to $19.7 \%$ at 1 month postoperatively and $10.0 \%$ at 1 year postoperatively. Relatively older patients $(p=0.005)$ and those $\geq 60$ years old $(p=0.001)$ experienced larger numbers of failures compared to younger patients. An analysis of potentially contributing comorbid conditions indicated that significantly more patients with diabetes were present in the PELD failure group $(p=0.017)$. As surgeons gained familiarity with the procedure, outcomes improved. The failure rate during the authors' early use of the PELD technique (Cases $1-70)$ was $17.1 \%$; the failure rate then fell to $5.7 \%(p=0.034)$ (Cases $141-210)$ before finally stabilizing at $10.0 \%$ (Cases 211-280 and Cases 281-350).

CONCLUSIONS The surgical failure rate following PELD for LDH was $10.3 \%$. Older patients, elderly patients (age $\geq 60$ years), and patients with diabetes were at increased risk of surgical failure of PELD, particularly in the early years of the procedure's use.

http://thejns.org/doi/abs/10.3171/2014.10.SPINE1442

KEY WORDS lumbar disc herniation; minimally invasive spinal surgery; percutaneous endoscopic lumbar discectomy; risk factors; surgical failure

工 IKE other surgical techniques, minimally invasive spinal procedures have become increasingly popular with both spine surgeons and their patients who undergo surgery for lumbar disc herniation (LDH). Since the introduction of percutaneous endoscopic lumbar discectomy (PELD), many investigators have reported concerns about the technique as well as the clinical outcomes of endoscopic discectomy. ${ }^{4,8,12,17}$ Although good surgical outcomes have been reported for this endoscopic approach to treat $\mathrm{LDH}$, the procedure still appears to be relatively complicated for most surgeons, and operative failures and

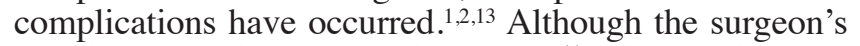
learning curve is steeper with PELD,${ }^{11}$ this technique allows enhanced visualization through a small skin incision, which causes minimal disruption to the posterior muscles. In addition to previous studies about operative failure and complications following PELD, $, 2,13$ only 1 study to date has assessed the failure of PELD treatment from the per-

\footnotetext{
ABBREVIATIONS LDH = lumbar disc herniation; ODI = Oswestry Disability Index; PELD = percutaneous endoscopic lumbar discectomy; VAS = visual analog scale. SUBMITTED January 13, 2014. ACCEPTED October 17, 2014.

INCLUDE WHEN CITING Published online June 12, 2015; DOI: 10.3171/2014.10.SPINE1442.

DISCLOSURE The authors report no conflict of interest concerning the materials or methods used in this study or the findings specified in this paper. This work was supported by the Chinese National High Technology Research Development Program (2011AA030106), the Key Project of the Chinese Ministry of Health (201002018), the Foundation of the State Key Laboratory of Robotics (2014-012), and the Medjaden Academy \& Research Foundation for Young Scientists (MJR20150013).

${ }^{*}$ Drs. Wang and Zhou contributed equally to this work.
} 
spective of evidence provided by radiological studies. ${ }^{13}$ In the present study, we retrospectively reviewed our experience to provide further insights into the rate of surgical failure following PELD. Moreover, we sought to identify the associated risk factors for surgical failure, including demographic, clinical, and radiologically identified factors.

\section{Methods \\ Patient Population}

A consecutive cohort of 350 patients with single-level LDH who underwent PELD using the Yeung Endoscopic Spine System (Richard Wolf Medical Instrument Co.) between 2005 and 2011 were included in this retrospective study. The patients were treated at Xinqiao Hospital, Chongqing, by 2 surgeons (Y.Z. and C.L.) who used the same surgical technique at the same institution during the study period. The procedure was approved by the Ethics Committee of The Third Military Medical University, and participants provided written informed consent to participate in this study. Operative failure was defined as follows: 1) LDH that required subsequent surgery because of persistent or recurrent symptoms within 6 months after surgery; 2) no pain-free interval from the first operation to the subsequent procedure; or 3) radiological verification of remnant fragments..$^{13}$ The exclusion criteria were as follows: 1) subsequent surgery because of recurrent symptoms after more than 6 months of a pain-free period following the PELD or 2) recurrent herniation after previous open lumbar surgery at the index level.

The medical records of the patients for whom we were able to appropriately determine recurrence status were also evaluated in order to identify demographic features, including age, sex, duration of symptoms, and history of trauma. In addition, patients with surgical failure were also assessed for the presence of comorbid conditions that could potentially interfere with postoperative healing (for example, steroid use) or could possibly predispose them to recurrence based on evidence reported in the discectomy literature (for example, trauma, tobacco use, or diabetes). In the current study, designated persons (1 nurse and 1 doctor) were assigned to contact the patients via telephone and email postoperatively at 1,3, 6, and 12 months to avoid patient loss to follow-up, so the entire cohort of 350 patients was followed up to the 12th month following surgery. Available preoperative images taken both before the initial surgery and prior to reoperation were reviewed and analyzed.

\section{Surgical Technique}

As noted, we used the Yeung Endoscopic Spine System, and the procedures were performed with the patients under local anesthesia in the prone position on a radiolucent table. Prior to surgery, the patients were informed about all of the steps of the procedure. The patients could also communicate with the surgeon during the entire procedure. After the application of local anesthesia with $1 \%$ lidocaine, an 18-gauge spinal needle was inserted into the outer fibers of the annulus fibrosus along a trajectory $15^{\circ}$ to $30^{\circ}$ from the sagittal plane under fluoroscopic guid- ance. The next steps were as follows: A guidewire was inserted through the spinal needle; the spinal needle was removed, and a small skin incision was made at the entry site; a tapered, cannulated obturator was inserted along the guidewire; after touching the annulus fibrosus, the obturator was inserted into the disc after the annulotomy was performed; and finally, a bevel-ended, oval-shaped working cannula was inserted into the disc along the obturator, and then the obturator was removed. Manual discectomy was performed through the cannula under fluoroscopic guidance. The Yeung Endoscopic Spine System endoscope was inserted through the cannula, and the herniated disc was removed with a small forceps and a side-firing holmium:yttrium-aluminum-garnet laser. Homeostasis and torn fibrous annulus repair were achieved using bipolar radiofrequency $\left(60^{\circ}-65^{\circ}\right)$. After removing the distinctive herniated fragment, we withdrew the endoscope and applied a sterile dressing with a one-point suture.

\section{Statistical Analysis}

Only the data obtained for those patients who could be adequately evaluated for surgical failure using our proposed guidelines were included in the analysis. Patients who did not suffer surgical failure following PELD for single-level LDH were evaluated for the comorbidities previously identified. In order to identify potential risk factors associated with surgical failure, we used these findings, when available, in comparisons with the findings for the surgical failure group. Using SPSS 15.0 (IBM), the Student t-test was performed for continuous variables, and chi-square analyses and Fisher's exact tests (contingency table analyses) were used for categorical variables depending on the sample size.

\section{Results}

In the 350-patient cohort, all of the patients had followup of more than 1 year since their PELD. The mean preoperative visual analog scale (VAS) scores of pain and the Oswestry Disability Index (ODI $)^{6}$ scores improved significantly from $6.6 \pm 2.1$ and $51.6 \pm 19.4$, respectively, to $1.9 \pm$ 1.4 and $28.3 \pm 12.0$, respectively, 1 month postoperatively and to $1.2 \pm 1.1$ and $9.3 \pm 7.8$, respectively, 1 year postoperatively. There were significant differences between the preoperative and postoperative groups in regard to the VAS and ODI scores. Among all patients, the frequencies of analgesic medication use significantly decreased from $74.6 \%$ preoperatively to $19.7 \%$ at 1 month postoperatively and $10.0 \%$ at 1 year postoperatively (Table 1 ).

We were able to definitively assess surgical failure by means of the medical record documentation or by telephone conversations and emails for all patients in the cohort. Among this group of patients, we identified 36 who suffered surgical failure following PELD (Table 2). No other complications were present. The majority of the patients were male (61.1\%), and the most common disc space involved was L4-5. Although 33 patients had returned to their preoperative level of functioning and activity before their second surgery and were operated on the initial surgical side, 3 patients who underwent second surgery on the opposite side presented with contralateral limb symptoms. 
TABLE 1. Preoperative and postoperative VAS and ODI scores, and analgesic medication usage

\begin{tabular}{|c|c|c|c|c|c|c|c|c|c|}
\hline \multirow[b]{2}{*}{ Characteristic } & \multicolumn{3}{|c|}{ VAS Scores (mean \pm SD) } & \multicolumn{3}{|c|}{ ODI Scores (mean \pm SD) } & \multicolumn{3}{|c|}{ Analgesic Medication Usage (\%) } \\
\hline & Preop & $\begin{array}{c}1 \text { Mo } \\
\text { Postop }\end{array}$ & $\begin{array}{c}1 \mathrm{Yr} \\
\text { Postop }\end{array}$ & Preop & $\begin{array}{c}1 \mathrm{Mo} \\
\text { Postop }\end{array}$ & $\begin{array}{c}1 \mathrm{Yr} \\
\text { Postop }\end{array}$ & Preop & $\begin{array}{c}1 \mathrm{Mo} \\
\text { Postop }\end{array}$ & $\begin{array}{c}1 \mathrm{Yr} \\
\text { Postop }\end{array}$ \\
\hline Nonfailure group $(n=314)$ & $6.6 \pm 2.1$ & $1.7 \pm 1.3$ & $1.1 \pm 1.1$ & $51.7 \pm 19.4$ & $27.7 \pm 12.0$ & $9.1 \pm 7.7$ & $234(74.5 \%)$ & $55(17.5 \%)$ & $31(9.9 \%)$ \\
\hline Failure group $(n=36)$ & $6.5 \pm 1.9$ & $3.9 \pm 0.7$ & $1.3 \pm 1.6$ & $51.1 \pm 18.6$ & $33.3 \pm 10.7$ & $11.4 \pm 8.7$ & $27(75.0 \%)$ & $14(38.9 \%)$ & $4(11.1 \%)$ \\
\hline Total $(n=350)$ & $6.6 \pm 2.1$ & $1.9 \pm 1.4$ & $1.2 \pm 1.1$ & $51.6 \pm 19.4$ & $28.3 \pm 12.0$ & $9.3 \pm 7.8$ & $261(74.6 \%)$ & $69(19.7 \%)$ & $35(10.0 \%)$ \\
\hline
\end{tabular}

One patient reported a traumatic event that precipitated the surgical failure. Twenty-one patients presented with postoperative residual pain due to a residual herniated disc or nerve injury without having experienced a postoperative period of symptom-free relief. Thirteen patients presented with postoperative recurrent pain due to a residual herniated disc or nerve root compression following a period of symptom-free relief (mean 1.9 months, range 0 days to 6 months), and 2 patients presented with postoperative pain due to infection of the intervertebral space (at 1 month and 1 week after the first operation). The latter 2 patients were diagnosed using preoperative MRI as well as examination of their erythrocyte sedimentation rate, C-reactive protein level, and neutrophil count. Two typical cases from the cohort are illustrated in Figs. 1 and 2.

According to the demographic factors (Table 3), we found that patients with surgical failure were significantly older (mean age 51.3 years) compared with patients without surgical failure (mean age 44.6 years) $(\mathrm{p}=0.005)$. The number and percentage of elderly patients (age $\geq 60$ years) in the surgical failure group $(12,33.3 \%)$ were also significantly higher compared with patients in the nonfailure group $(38,12.1 \%)$ ( $\mathrm{p}=0.001$, chi-square analysis and Fisher's exact test). An analysis of the potentially contributing comorbid conditions in patients with surgical failure indicated the presence of significantly more patients with diabetes in the failure group $(p=0.017)$. In terms of clinical and radiologically identified factors (Tables 4 and 5, respectively), we found no significant differences between the surgical failure group and the nonfailure group. The failure rate during the early use of the PELD technique (Cases 1-70) was 17.1\%, which then fell to 5.7\% (Cases 141-210) before finally stabilizing at $10.0 \%$ (Cases 211-

TABLE 2. Characteristics of patients who suffered LDH surgical failure following PELD

\begin{tabular}{lcc}
\hline \multicolumn{1}{c}{ Characteristic } & $\begin{array}{c}\text { No. of } \\
\text { Patients }\end{array}$ & $\begin{array}{c}\text { Frequency } \\
(\%)\end{array}$ \\
\hline PELD failure with SFR & 21 & 6.0 \\
\hline PELD failure without SFR & 13 & 3.7 \\
\hline Postoperative neurological deficits & 3 & 0.8 \\
\hline Postoperative residual symptoms & 10 & 2.9 \\
\hline Postoperative infection & 2 & 0.6 \\
\hline Hematoma & 0 & 0 \\
\hline CSF leak & 0 & 0 \\
\hline
\end{tabular}

SFR = symptom-free relief; CSF = cerebrospinal fluid.
280 and Cases 281-350) (Fig. 3). Each case series included 70 patients, and the dates for each series were as follows: Cases 1-70, September 2005-December 2007; Cases 71-140, December 2007-November 2008; Cases 141-210, November 2008-August 2009; and Cases 211-280, August 2009-August 2010.

\section{Discussion}

The rate of surgical failure differed significantly according to the mean age, greater age ( $\geq 60$ years), a potentially contributing comorbidity (diabetes), and the level of the LDH. The surgical failure rate following PELD for LDH was $10.3 \%$. Although several investigators have reported outcomes for PELD, there are few reports about the failure of the procedure. Schaffer and Kambin ${ }^{18}$ noted that 11 of 100 patients treated by PELD underwent reoperation, and, of these 11 patients, 5 had persistent symptoms after endoscopic surgery. In addition, the most common causes for subsequent surgery in the 11 patients were lateral recess stenosis, sequestered herniation, and improper placement of the working instruments. Lee et al. ${ }^{13}$ showed that disc herniation with high-grade canal compromise and high-grade migration were associated with a significantly higher incidence of operative failure. However, these studies did not examine the demographic and clinical factors that may have resulted in or contributed to operative failure. Based on the findings of our study, the surgical results of PELD can also be affected by the ages of the patients and by potentially contributing comorbidities.

Risk factors for LDH recurrence have been previously identified in patients who have undergone open discecto-
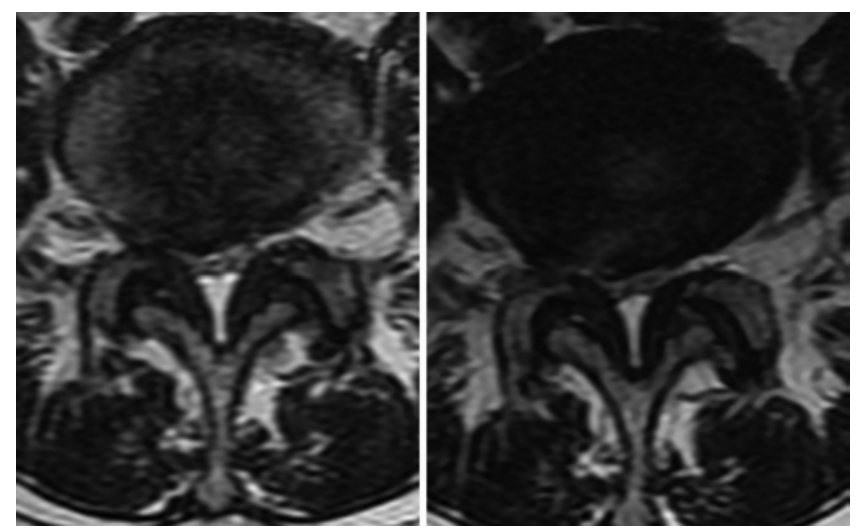

FIG. 1. Preoperative (left) and postoperative (right) MR images demonstrating successful disc removal with PELD. 

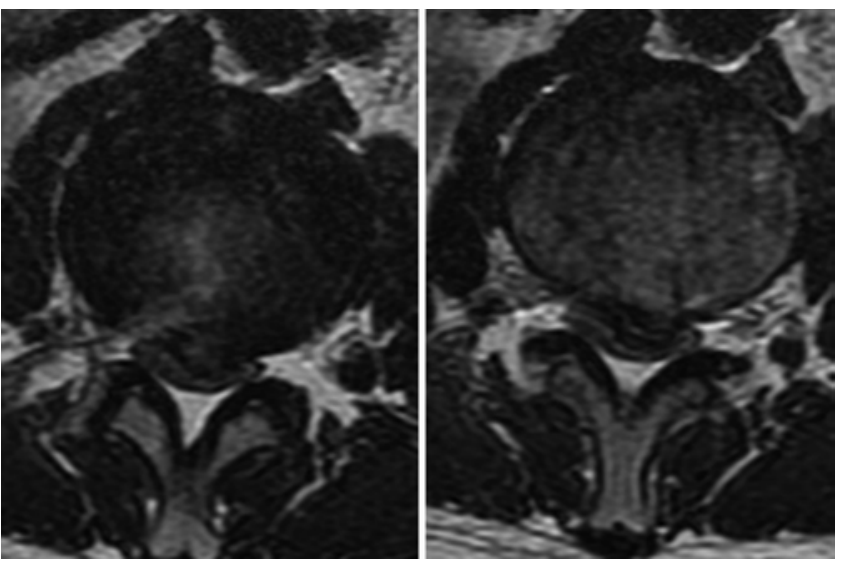

FIG. 2. Preoperative (left) and postoperative (right) MR images demonstrating a case in which the patient required reoperation.

my, microscope-assisted tubular lumbar microdiscectomy, or PELD, but systematic studies have not previously evaluated risk factors for surgical failure in LDH. Risk factors for LDH recurrence include young age, male sex, smoking, and a history of trauma. ${ }^{5,19}$ Moliterno et al. ${ }^{15}$ showed that nonobese patients, particularly those with a relatively low body mass index, appeared to be at greater risk for recurrence following microscope-assisted tubular lumbar microdiscectomy. In addition to worse overall outcomes and prolonged hospitalizations, diabetic patients have also been found to have a higher incidence of LDH recurrence. ${ }^{14}$ An analysis of the actual disc material found that the proteoglycans in diabetic patients' discs have a lower

TABLE 3. Demographic factors that affected surgical failures

\begin{tabular}{|c|c|c|c|}
\hline Characteristic & $\begin{array}{l}\text { Nonfailure } \\
\text { Group }\end{array}$ & $\begin{array}{l}\text { Failure } \\
\text { Group }\end{array}$ & $\begin{array}{c}\mathrm{p} \\
\text { Value }\end{array}$ \\
\hline No. of cases & 314 & 36 & \\
\hline Sex (M:F) & $178: 136$ & $22: 14$ & 0.611 \\
\hline Mean age in yrs $( \pm S D)$ & $44.6 \pm 13.6$ & $51.3 \pm 13.7$ & 0.005 \\
\hline $16-40$ yrs $(\%)^{*}$ & $112(35.7)$ & $7(19.4)$ & 0.052 \\
\hline $40-60$ yrs $(\%)^{*}$ & $164(52.2)$ & $17(47.2)$ & 0.569 \\
\hline$\geq 60$ yrs $(\%)^{*}$ & $38(12.1)$ & $12(33.3)$ & 0.001 \\
\hline $\begin{array}{l}\text { Mean duration of symptoms in } \\
\quad \text { yrs }( \pm \text { SD) }\end{array}$ & $34.4 \pm 54.2$ & $45.6 \pm 91.3$ & 0.475 \\
\hline$\leq 3 \mathrm{yrs}(\%)^{*}$ & $53(16.9)$ & $5(13.9)$ & 0.648 \\
\hline $3-6$ yrs $(\%)^{*}$ & $34(10.8)$ & $7(19.4)$ & 0.212 \\
\hline $6-12$ yrs (\%)* & $57(18.2)$ & $5(13.9)$ & 0.526 \\
\hline$>12$ yrs $(\%)^{*}$ & $170(54.1)$ & $19(52.8)$ & 0.877 \\
\hline \multicolumn{4}{|l|}{$\begin{array}{l}\text { Potentially contributing comor- } \\
\text { bidities }\end{array}$} \\
\hline Tobacco use* & $37(11.8)$ & $3(8.3)$ & 0.734 \\
\hline Diabetes* & $7(2.2)$ & $4(11.1)$ & 0.017 \\
\hline Steroid use* & 0 & 0 & - \\
\hline History of trauma* & $42(13.4)$ & $7(19.4)$ & 0.320 \\
\hline
\end{tabular}

$-=$ not applicable.

* Values are presented as the number (\%) of patients.
TABLE 4. Clinical factors that affected surgical failures

\begin{tabular}{|c|c|c|c|}
\hline \multirow[b]{2}{*}{ Characteristic } & \multicolumn{2}{|c|}{ No. of Patients (\%) } & \multirow[b]{2}{*}{$\begin{array}{c}p \\
\text { Value }\end{array}$} \\
\hline & $\begin{array}{l}\text { Nonfailure } \\
\text { Group }\end{array}$ & $\begin{array}{l}\text { Failure } \\
\text { Group }\end{array}$ & \\
\hline No. of cases & 314 & 36 & \\
\hline \multicolumn{4}{|l|}{ Clinical symptoms } \\
\hline Back pain dominant & $111(35.4)$ & $15(41.7)$ & 0.455 \\
\hline Leg pain dominant & $52(16.6)$ & $4(11.1)$ & 0.398 \\
\hline Leg pain \& back pain & $151(48.1)$ & $17(47.2)$ & 0.921 \\
\hline \multicolumn{4}{|l|}{ Physical examination } \\
\hline $\begin{array}{l}\text { Tenderness \& radiating sciatic } \\
\text { pain }\end{array}$ & $94(29.9)$ & $13(36.1)$ & 0.446 \\
\hline $\begin{array}{l}\text { Muscle strength weakness (toe } \\
\text { extensors) }\end{array}$ & $176(56.1)$ & $17(47.2)$ & 0.313 \\
\hline Reactive scoliosis & $16(5.1)$ & $2(5.6)$ & 1.000 \\
\hline $\begin{array}{l}\text { Flattening of sagittal spinal } \\
\text { curvature }\end{array}$ & $84(26.8)$ & $8(22.2)$ & 0.282 \\
\hline Decreased reflex & $107(34.1)$ & $9(25.0)$ & 0.272 \\
\hline Positive leg-raising test & $216(68.8)$ & $27(75.0)$ & 0.444 \\
\hline
\end{tabular}

buoyant density than do the proteoglycans of nondiabetic patients, which could potentially lead to an increased susceptibility to disc prolapse in the former population. . $^{14,16,21}$ Kim et al. ${ }^{9}$ showed that mean age and body mass index among patients in the recurrence group following PELD were significantly higher than those in the nonrecurrence

TABLE 5. Radiologically identified factors that affected surgical failures

\begin{tabular}{cccc}
\hline & \multicolumn{2}{c}{ No. of Patients (\%) } & \\
\cline { 2 - 3 } Characteristic & $\begin{array}{c}\text { Nonfailure } \\
\text { Group }\end{array}$ & $\begin{array}{c}\text { Failure } \\
\text { Group }\end{array}$ & $\begin{array}{c}\text { p } \\
\text { Value }\end{array}$ \\
\hline Number of cases & $314(100)$ & $36(10.3)$ & - \\
\hline Level of LDH & & & \\
\hline L2-3 & $4(1.3)$ & 0 & 1.000 \\
\hline L3-4 & $12(3.8)$ & 0 & 0.478 \\
\hline L4-5 & $210(66.9)$ & $30(83.3)$ & 0.044 \\
\hline L5-6 & $6(1.9)$ & 0 & 0.874 \\
\hline L5-S1 & $82(26.1)$ & $6(16.7)$ & 0.216 \\
\hline Type of LDH & & & \\
\hline Contained & $244(77.7)$ & $29(80.6)$ & $0.696^{*}$ \\
\hline Uncontained & $70(22.3)$ & $7(19.4)$ & \\
\hline Location of LDH & & & \\
\hline Central & $102(32.5)$ & $15(41.7)$ & 0.269 \\
\hline Posterolateral & $162(51.6)$ & $17(47.2)$ & 0.619 \\
\hline Foraminal & $50(15.9)$ & $4(11.1)$ & 0.449 \\
\hline Bony stenosis & & & \\
\hline Lateral recess stenosis & $67(21.3)$ & $5(13.9)$ & 0.295 \\
\hline Foraminal stenosis & $64(20.4)$ & $9(25.0)$ & 0.518 \\
\hline * = not applicable. & & & \\
* p value for comparison of contained vs uncontained LDH. & \\
\hline
\end{tabular}




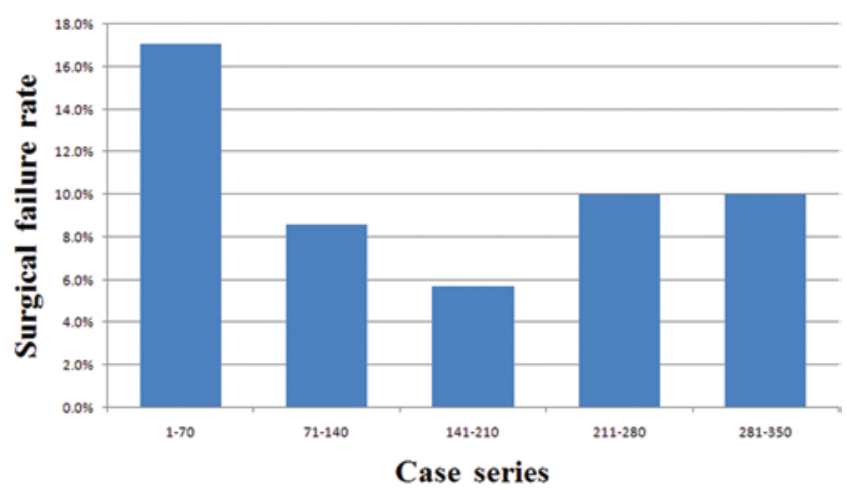

FIG. 3. Surgical failure rates of different case series. Each case series included 70 patients, and the dates for each series were as follows: Cases 1-70, September 2005-December 2007; Cases 71-140, December 2007-November 2008; Cases 141-210, November 2008-August 2009; and Cases 211-280, August 2009-August 2010. Figure is available in color online only.

group ( $p=0.001$ and $p=0.006$, respectively). This result is considered reasonable, and because older patients typically show more disc degeneration, the recurrence rate could be higher for the reasons that Cinotti et al. noted: The remaining nucleus in the annulus is easily susceptible to prolapse when mechanically overloaded due to an annular incision during the operation..$^{5}$ In our study, in comparison with patients who did not experience surgical failure, relatively older patients, particularly elderly patients (age $\geq 60$ years), were at a significantly increased risk of surgical failure. We believe that the elderly patients could not accurately express their feelings during surgery when the herniated disc was being removed, and older patients typically show more disc degeneration and severe bony degeneration. During endoscopic surgery, the surgeon's view is limited, and it is especially difficult to remove hidden fragments that are located beyond the working channel. Further, residual disc materials may be located at the contralateral or ipsilateral side, causing surgical failure. In our study, the 3 patients who presented with contralateral disc herniation after the first operation were all elderly patients.

With respect to the clinical and radiologically identified factors that affect surgical failure, Kleinstueck et al. ${ }^{10}$ noted that patients with more back pain showed significantly worse outcomes after decompressive surgery for LDH. This finding fits with general clinical experience but has rarely been quantified in the many predictive studies that have been conducted to date. Suzuki et al. ${ }^{20}$ have reported that uncontained herniation and migrated herniated nucleus pulposus are the most important risk factors for motor deficit in LDH and that severe motor deficits and uncontained herniations are associated with delayed recovery. In the current study, we found no clinical or radiologically identified risk factors for surgical failure following PELD. In our study, there were few cases with concurrent osseous lateral recess stenosis, which could be regarded as a technical limitation. ${ }^{3}$ As reported elsewhere, ${ }^{7,22}$ a herniated fragment is accessible only when the surgical instrument is placed in the optimal trajectory. This indicates that the adequate removal of a large herniation via the percutane- ous endoscopic technique is technically demanding and can be affected by the surgeon's experience. As mentioned previously, an experienced endoscopic surgeon may be able to overcome some of the obstacles regarding herniations and thus may avoid high failure rates. Data from our study support this observation.

\section{Conclusions}

We performed 350 consecutive single-level PELDs and found definitive surgical failure in $36(10.3 \%)$ of the 350 patients about whom we were able to ascertain surgical failure status via a medical chart review. Older patients, particularly elderly patients (age $\geq 60$ years), patients who presented with diabetes, and patients who underwent PELD early in our series were at increased risk for surgical failure of PELD.

\section{References}

1. Ahn Y, Kim JU, Lee BH, Lee SH, Park JD, Hong DH, et al: Postoperative retroperitoneal hematoma following transforaminal percutaneous endoscopic lumbar discectomy. J Neurosurg Spine 10:595-602, 2009

2. Ahn Y, Lee HY, Lee SH, Lee JH: Dural tears in percutaneous endoscopic lumbar discectomy. Eur Spine J 20:58-64, 2011

3. Ahn Y, Lee SH, Park WM, Lee HY, Shin SW, Kang HY: Percutaneous endoscopic lumbar discectomy for recurrent disc herniation: surgical technique, outcome, and prognostic factors of 43 consecutive cases. Spine (Phila Pa 1976) 29:E326-E332, 2004

4. Choi G, Lee SH, Bhanot A, Raiturker PP, Chae YS: Percutaneous endoscopic discectomy for extraforaminal lumbar disc herniations: extraforaminal targeted fragmentectomy technique using working channel endoscope. Spine (Phila Pa 1976) 32:E93-E99, 2007

5. Cinotti G, Gumina S, Giannicola G, Postacchini F: Contralateral recurrent lumbar disc herniation. Results of discectomy compared with those in primary herniation. Spine (Phila Pa 1976) 24:800-806, 1999

6. Fairbank JC, Pynsent PB: The Oswestry Disability Index. Spine (Phila Pa 1976) 25:2940-2952, 2000

7. Hermantin FU, Peters T, Quartararo L, Kambin P: A prospective, randomized study comparing the results of open discectomy with those of video-assisted arthroscopic microdiscectomy. J Bone Joint Surg Am 81:958-965, 1999

8. Jang JS, An SH, Lee SH: Transforaminal percutaneous endoscopic discectomy in the treatment of foraminal and extraforaminal lumbar disc herniations. J Spinal Disord Tech 19:338-343, 2006

9. Kim JM, Lee SH, Ahn Y, Yoon DH, Lee CD, Lim ST: Recurrence after successful percutaneous endoscopic lumbar discectomy. Minim Invasive Neurosurg 50:82-85, 2007

10. Kleinstueck FS, Fekete T, Jeszenszky D, Mannion AF, Grob $\mathrm{D}$, Lattig F, et al: The outcome of decompression surgery for lumbar herniated disc is influenced by the level of concomitant preoperative low back pain. Eur Spine J 20:1166-1173, 2011

11. Lee DY, Lee SH: Learning curve for percutaneous endoscopic lumbar discectomy. Neurol Med Chir (Tokyo) 48:383-389, 2008

12. Lee SH, Chung SE, Ahn Y, Kim TH, Park JY, Shin SW: Comparative radiologic evaluation of percutaneous endoscopic lumbar discectomy and open microdiscectomy: a matched cohort analysis. Mt Sinai J Med73:795-801, 2006

13. Lee SH, Kang BU, Ahn Y, Choi G, Choi YG, Ahn KU, et al: 
Operative failure of percutaneous endoscopic lumbar discectomy: a radiologic analysis of 55 cases. Spine (Phila Pa 1976) 31:E285-E290, 2006

14. Mobbs RJ, Newcombe RL, Chandran KN: Lumbar discectomy and the diabetic patient: incidence and outcome. J Clin Neurosci 8:10-13, 2001

15. Moliterno JA, Knopman J, Parikh K, Cohan JN, Huang QD, Aaker GD, et al: Results and risk factors for recurrence following single-level tubular lumbar microdiscectomy. J Neurosurg Spine 12:680-686, 2010

16. Robinson D, Mirovsky Y, Halperin N, Evron Z, Nevo Z: Changes in proteoglycans of intervertebral disc in diabetic patients. A possible cause of increased back pain. Spine (Phila Pa 1976) 23:849-856, 1998

17. Sasani M, Ozer AF, Oktenoglu T, Canbulat N, Sarioglu AC: Percutaneous endoscopic discectomy for far lateral lumbar disc herniations: prospective study and outcome of $66 \mathrm{pa}-$ tients. Minim Invasive Neurosurg 50:91-97, 2007

18. Schaffer JL, Kambin P: Percutaneous posterolateral lumbar discectomy and decompression with a 6.9-millimeter cannula. Analysis of operative failures and complications. J Bone Joint Surg Am 73:822-831, 1991

19. Suk KS, Lee HM, Moon SH, Kim NH: Recurrent lumbar disc herniation: results of operative management. Spine (Phila Pa 1976) 26:672-676, 2001

20. Suzuki A, Matsumura A, Konishi S, Terai H, Tsujio T, Dozono S, et al: Risk factor analysis for motor deficit and delayed recovery associated with L4/5 lumbar disc herniation. J Spinal Disord Tech 24:1-5, 2011

21. Swartz KR, Trost GR: Recurrent lumbar disc herniation. Neurosurg Focus 15(3):E10, 2003

22. Yeung AT, Tsou PM: Posterolateral endoscopic excision for lumbar disc herniation: surgical technique, outcome, and complications in 307 consecutive cases. Spine (Phila Pa 1976) 27:722-731, 2002

\section{Author Contributions}

Conception and design: all authors. Acquisition of data: all authors. Analysis and interpretation of data: all authors. Drafting the article: all authors. Critically revising the article: all authors. Reviewed submitted version of manuscript: all authors. Approved the final version of the manuscript on behalf of all authors: Xiang. Statistical analysis: Xiang, Wang, Zhou, Liu. Administrative/technical/material support: Xiang, Wang, Zhou, Liu. Study supervision: Xiang, Wang, Zhou, Liu.

\section{Correspondence}

Liangbi Xiang, Department of Orthopedics, General Hospital of Shenyang Military Area Command of Chinese PLA, Shenyang, 110016 Liaoning, China. email: xiangliangbi1963@163.com. 